\title{
THE IDENTIFICATION OF COPY NUMBER VARIATION OF CNV ESV27061 AMONG YOUNG ADULTS WITH HYPERTENSION: PRELIMINARY FINDINGS
}

Siti Radziah Shaik Alaudeen ${ }^{1}$, Azarisman Shah Mohd Shah ${ }^{2}$, Norlelawati Abdul Talib ${ }^{3}$ and Aszrin Abdullah ${ }^{1}$

${ }^{1}$ Department of Basic Medical Sciences, Kulliyyah of Medicine, International Islamic University Malaysia, Pahang, Malaysia, ${ }^{2}$ Department of Internal Medicine, Kulliyyah of Medicine, International Islamic University Malaysia, Pahang, Malaysia, ${ }^{3}$ Department of Pathology and Laboratory Medicine, Kulliyyah of Medicine, International Islamic University Malaysia, Pahang, Malaysia,

Presenter: Siti Radziah, sitiradziah@yahoo.com

Introduction: Hypertension related morbidities and mortalities around the world show a gradual increase and early detection and prevention are advocated. The Database of Genomic Variants (DGV) has associated variation in DNA sequences called copy number variation (CNV) with susceptibility to common diseases. However, little is known about CNV role in essential hypertension. Thus, this study aimed to characterize the CNV esv27061 among prehypertensive and hypertensive young adults in Malaysia.

Materials and method: In this comparative cross-sectional study, 104 subjects living in Kuantan who gave voluntary consent to participate are recruited and divided into three groups; control (43 subjects), prehypertensive ( 38 subjects) and mild hypertensive (23 subjects). An optimized droplet digital polymerase chain reaction (ddPCR) was used in the determination of CNV esv27061 in this study.

Results: All subjects in the control ( $n=38 ; 88.4 \%$ gain), prehypertensive $(n=33 ; 86.8 \%$ gain) and mild hypertensive ( $\mathrm{n}=21 ; 91.3 \%$ gain) groups had CNV gain (copy number $>2$ ) while $11.6 \%$ of control, $13.2 \%$ of prehypertensive and $8.7 \%$ of mild hypertensive subjects exhibited normal copies (copy number $=2$ ).

Conclusion: The present preliminary finding was consistent with the Database of Genomic Variants (DGV) which stated that CNV esv27061 showed more gain than loss. 